\title{
Chromosomal Rearrangements of RET/PTC in Post-Chernobyl Thyroid Cancer
}

\author{
Sergei V. Jargin ${ }^{1, *}$ \\ ${ }^{1}$ Department of Public Health, Peoples' Friendship University of Russia, \\ Moscow, Russia \\ *Corresponding author: Sergei V. Jargin, Department of Public Health, \\ Peoples' Friendship University of Russia, 117198 Moscow, Russia. Tel: \\ +74959516788; Fax: +74959516788; E-mail: sjargin@mail.ru
}

DOI: $10.30699 /$ mci.4.2.28

\begin{abstract}
Submitted:14 December 2019
Revised: 19 January 2020

Abstract

A hypothesis is proposed here that RET rearrangements in papillary thyroid cancers are related to the disease duration and tumor progression. The most common RET

Accepted: 5 February 2020 rearrangements are $\mathrm{RET} / \mathrm{PTC} 1$ and $\mathrm{RET} / \mathrm{PTC} 3 . \mathrm{RET} / \mathrm{PTC} 1$ is more prevalent in

e-Published: 1 April 2020 classic papillary thyroid carcinoma (PTC), its diffuse sclerosing variant, and papillary microcarcinoma; while RET/PTC3 is frequently found in less differentiated solid PTC.

Keywords:

Radiation, Ionizing

Chernobyl Nuclear Accident

Thyroid Neoplasms RET/PTC3 is associated with larger tumor size and multifocality in sporadic pediatric PTC. The RET rearrangements; especially RET/PTC3, which is frequently detected among Chernobyl thyroid cancers is developed after exposure to radiation at an early age, is proposed to be a potential trigger of malignancy. There are many late-stage tumors among the first-wave Chernobyl PTCs that tend to be larger and less differentiated than those detected later. The high proportion of late-stage cases shortly after the accident is explained by the neglected cases in the screening process and also by the fact that some non-exposed patients were registered as radiation-exposed. The screening was productive because of the reservoir of undiagnosed cases in the population: registered incidence of thyroid cancer (TC) among children and adolescents prior to the Chernobyl disaster was low in the Soviet Union; compared to other developed countries. In conclusion, RET rearrangements, especially RET/PTC3, were correlated with the tumor progression. If the hypothesis defended here is correct, a low prevalence of RET/PTC3 among sporadic TC is circumstantial evidence of efficient cancer diagnosis and early detection.
\end{abstract}

(C) 2020. Multidisciplinary Cancer Investigation

\section{INTRODUCTION}

The proto-oncogene RET (rearranged during Transfection) encodes a tyrosine kinase receptor. Chromosomal rearrangements that produce fusion genes and activate the proto-oncogene are named RET/PTC after the gene RET and papillary thyroid carcinoma (PTC). The reported frequency of RET/PTC rearrangements (fusions) among all PTCs was estimated to be around $28 \%[1,2]$. There are different RET rearrangements such as RET/PTC1 and RET/PTC3 as the most prevalent types $[2,3]$. RET/PTC3 was associated with the solid morphologic variant of PTC, larger tumor size, and multifocality in sporadic pediatric PTC [4]. Generally, RET rearrangements are more prevalent in classic PTC than in the follicular type which may be caused by distinct oncogenic pathways and/or by an admixture of true follicular thyroid cancers (TC). Approximately, 9\% of poorly differentiated thyroid carcinomas harbor RET/PTC [2]; indicating that some of them are developed from PTC with RET fusions [1]. The potential role of RET mutations in non-papillary 
thyroid tumors is beyond the scope of this communication. A hypothesis is proposed here that RET rearrangements in PTC are related to the disease duration and tumor progression. In this regards RET/PTC3 is associated with late-stage tumors as compared with RET/PTC1. PubMed and Russian-language databases were applied for the literature review; using RET/PTC and thyroid cancer as the keywords. Lack of enough data in epidemiological research of low-dose radiation and inter-study heterogeneity i.e. uneven quality of studies analyzed together in reviews and metaanalyses are among the potential biases [5-7]. The reliability of research is sometimes difficult to be evaluated. According to Little et al., studies of questionable reliability "should therefore probably not be used for epidemiologic analysis, in particular [8-12]". The exaggeration of the medical consequences of the Chernobyl disaster and other radioactive contaminations were previously discussed [13-17]. Overestimated numbers of radiogenic cancers were served as a motive to search for markers of radiation-related malignancies; while RET rearrangements were the main candidates for this role. The core hypothesis presented in this research and preceding papers was that some neglected TCs have been misinterpreted after the Chernobyl accident as rapidly growing radiogenic cancers [13-17]. Accordingly, the supposed markers of radiogenic etiology are in fact associated with longer disease duration and tumor progression. This concept has more general implications: if it is correct, a low percentage of RET/PTC3 among spontaneous TCs could be considered as circumstantial evidence of efficient diagnosis and early tumor detection in different countries.

\section{Association of RET/PTC With Radiogenic and Advanced TCs}

The RET fusions, especially RET/PTC3, are frequently found in PTC of patients who have been exposed to the Chernobyl disaster at an early age $[18,19]$. These markers are supposed to be potential indicators of radiation-related TCs [20]. There was an association between RET/PTC3 and a solid histological structure that was prevailed in PTC during the first 10 years after the accident $[19,21]$. The years 1986-96 approximately corresponded to the "first wave" post-Chernobyl TCs $[18,19,21]$. There were many late-stage cancers among the first wave cases. In a study from Belorussia (1986-91, 86 pediatric TC), $61.5 \%$ of cases had high or intermediate grades of TC. In another study (1991-92, 84 pediatric TC), the cancers were reportedly aggressive, accompanied by intraglandular tumor dissemination (92\%), cervical lymph node metastases (88\%), and ingrowth into the capsule and surrounding tissues (89\%). In a study from Ukraine (1986-96, 244 pediatric TC), T4 (TNM stage) was found in about $50 \%$ of cases with a proportion of $66-71 \%$ in adolescents; more references are in the preceding review and the monograph $[13,15]$. It can be reasonably assumed that many of these tumors have been developed prior to the Chernobyl disaster. The first wave TCs tended to be larger and less differentiated than those detected later [21], one of the reasons may be the admixture of advanced cases. According to Yablokov et al., as a crucial study, Chernobyl TCs are more aggressive at early stages with high lymphatic invasiveness [22]. The thyroid screening after the Chernobyl disaster was yielding due to the reservoir of latestage cancers in the population: the detection rate of pediatric TC prior to the accident was lower in the Soviet Union (SU) than in other industrialized nations $[23,24]$. Besides, there was an endeavor to be recognized as victims of Chernobyl to avail of compensations). Cases from non-contaminated areas must have been averagely in more advanced stages due to the lack of screening modalities in those areas. The post-Chernobyl pediatric TC were predominantly of papillary type often containing areas with less differentiated solid and follicular patterns, indicating that the "first wave" post-Chernobyl TC was diagnosed averagely at a later stage. The RET/PTC fusions were associated with the T3-4 stages, local recurrence, and distant metastases [25]. These features in children and adolescents tended to correlate with RET/PTC3 rather than RET/PTC1 [20]. RET/PTC3 was associated with aggressiveness, larger dimensions, and later stages at diagnosis [1]. As mentioned above, the presence of RET/ PTC3 was often combined with larger tumor size and multifocality in sporadic PTC in pediatrics [4]. It was assumed that RET/PTC1 predispose 
the patient to subsequent RET rearrangements, RET/PTC3 being the next frequent one [26]. A majority of the first-wave PTCs after Chernobyl harbored RET/PTC3 fusions; while $63 \%$ of the cancers with RET/PTC3 were detected in the first decade after the disaster [19]. Conversely, RET/ PTC1 was predominant after 10 years. The firstwave TCs were less structurally differentiated than those found later [21]. With time passing after the accident, the proportion of cancers with RET rearrangements decreased, whereas in RETpositive cases the proportion of RET/PTC1 grew with a decrease in the prevalence of RET/PTC3 $[18,19]$. The percentage of late-stage cancers must have been higher among early post-accident cases when the reservoir of neglected tumors was still untapped.

As an exceptional finding, the cohort of pediatric PTC after the Chernobyl disaster with the predominance of RET/PTC3 was deemed unique worldwide [27]. On the contrary to Chernobyl, among sporadic PTC cases, the prevailing RET rearrangement was RET/PTC1 [3]. Of note, postChernobyl cancer is unique not for the whole world but for industrialized countries where the diagnosis is generally more efficient. As expected, RET/PTC3 was the most frequent RET fusion type in the studies from the Indian Subcontinent [28, 29]. Conversely, RET/PTC1 prevailed in PTCs that were developed after radiotherapy in France, whereas among sporadic cases both RET/PTC1 and RET/PTC3 were rare [30]. Analogously, pediatric TCs from Japan were considerably more differentiated than their counterparts from Ukraine and Belorussia including the Chernobyl area [31]. The prevalence of RET rearrangements in the Japanese pediatric TCs was relatively low; while RET/PTC1 was more predominant $[32,33]$. Of note, the prevalence of RET/PTC3 found by the screening after the Fukushima Daiichi nuclear accident was lower than sporadic Japanese cases [33]. The screening in Japan resulted in the detection of earlier cases, whereas the first wave post-Chernobyl screening found many neglected TCs which certifies the efficient diagnosis in Japan. In addition to the factors discussed here and in previous studies [13-17], the high-resolution ultrasound equipment used in Fukushima that was not available after the Chernobyl accident made its contribution to the early diagnosis [33]. The in vitro induction of RET fusions after cell irradiation was reported [20], but the doses in experiments were much higher than the averages in Chernobyl victims. The in vitro information on RET/PTC1 induction by doses as low as $0.1 \mathrm{~Gy}$ was singular [34]. Certain claims by Nikiforov, a leading co-worker of the research (34), ascribing the global growth of TCs incidence by the nuclear testing or accidents [35] are indicative of a bias discussed in previous papers $[14,15]$.

\section{DISCUSSION}

There is evidence that the frequency of RET/ PTC fusions, especially RET/PTC3, tends to correlate with the disease duration and a later stage of the tumor progression in PTC patients. In view of the clustering of rearranged cells, it was assumed that RET fusions are relatively late subclonal phenomenon [36], which agrees with the hypothesis discussed here. The RET/PTC3 were found much more frequently in Ukraine than in France [37]. A worldwide decrease in RET/ PTC incidence as well as in developed countries over the last decades [38, 39] along with the growing TC detection rate [32] could be attributed to the improving diagnostic technologies. The decreasing trend may be in fact even stronger in view of the growing sensitivity of RET/PTC detection methods [33].

A relationship between RET/PTC and individual doses of ionizing radiation was noticed among Chernobyl cases [40]. Tuttle et al., found no associations between RET/PTC and different doses [41]. It is known that correlation per se does not prove causality, being possibly resulted from the dependence of diagnostic quality and self-reporting from individual doses [14, 15]. Correlations between individual doses and RET rearrangements among atomic bomb survivors [40] could be caused by a similar bias as well as by higher doses than in Chernobyl victims. Note that acute exposures to low linear energy transfer (LET) radiation are generally more efficient than protracted ones [42]. The enhanced frequency of RET/PTC was noticed in PTC from patients who had undergone radiotherapy during childhood [43]. Many of them were treated for cancer so that the doses were much higher than average 
Chernobyl doses. The same fact pertains to the study [30], where the prevalence of RET/PTC in TC after radiotherapy for benign or malignant conditions was higher than that in sporadic cases. Of note, the hypothesis proposed here does not exclude a possibility of RET/PTC induction by radiation but foregrounds the accumulation of mutations with time and their association with certain steps of the tumor progression (RET/ PTC3 - with a later step). Despite the referencing of articles [16, 17] and debates at conferences, this hypothesis was not mentioned in the review [44], where it was claimed with the references [45-48] that RET/PTC is more frequent in occult cancers and microcarcinomas than in "mature tumors" [44]. The cited papers are not new (1995-2001); studies with different results and conclusions have been published since then. For example, in the study [48] from 1998, RET/PTC was reportedly not associated with the tumor size, extrathyroidal spread and metastasizing. However, in a later publication from the same institution, an association between high expression of RET/ PTC1 and the tumor size was pointed out [26]. Apparently, RET/PTC1 can appear relatively early in the course of the tumor progression whereas RET/PTC3 tends to arise later on.

Furthermore, there was a report on a higher proportion of RET/PTC (not further specified) and some other cytogenetic markers (BRAF, RAS, PAX8-PPAR $\gamma$ ) in T1 compared with T2-4 stages of PTC [25]. In the same paper, it is written that the RET/PTC-positivity was significantly associated with the T3-4 stages. We inquired about this discrepancy by the study published by Yip et al., [25] and received a comment from Yuri Nikiforov declaring that "It's in a way a moot point since the entire staging system has changed dramatically since 2015. RET/PTCpositive tumors are papillary carcinomas with the propensity to lymph node metastasis but tend to occur more often in younger patients. They are overall considered of intermediate American Thyroid Association (ATA) risk for recurrence" (e-mail communication 19 Sept. 2019). We responded to the following: "The staging system may have changed but any staging system reflects the tumor progression. Do the figures "RET/ PTC: T1- 57\%, T2-8\%, T3-22\%, T4-14\%” [25] mean that RET/PTC disappears with the tumor progression? If yes, why do they disappear? Are mutations not supposed to accumulate with the tumor progression? How then RET/PTC can correlate with the 'propensity to lymph node metastasis'? Is there indeed a discrepancy in the article [25] or maybe there was an artifact?" Yuri replied: "RET/PTC positive tumors rarely undergo dedifferentiation, the fusion (RET/PTC) is virtually never found in anaplastic thyroid carcinoma (ATC), so they rarely kill patients, yet can involve multiple lymph nodes and recur" (e-mail communication 20 Sept. 2019). It is known that malignant tumors generally tend to undergo progression. However, for PTC the progression does not mean a transformation to ATC probably because of different oncogenic pathways. More details and references are in the letter [49] commenting on the article [25]. Theoretically, a disappearance of RET/PTC-positive cells along with the tumor de-differentiation could be caused by a negative clonal selection due to the lower viability of mutation-bearing cells. Further research with reliable detection of both RET/ PTC1 and RET/PTC3 is needed. With regard to the data about associations of RET/PTC (RET/ PTC3 in particular) with a younger patients' age [50-52], it could be speculated that TC is detected in young people averagely at a later stage. This can be caused by lower oncological alertness (doctors less often think on cancer examining young patients) or by a more rapid tumor progression in younger individuals.

Many publications about Chernobyl, mentioned it as a matter-of-course that additional TC cases after the disaster were induced by the exposure to ionizing radiation i.e. certain studies looking for markers of radiogenic malignancies [53] were based on the premise that a large part of Chernobylrelated cancers was of radiogenic nature. In fact, some proposed markers of radiogenic postChernobyl cancer are probably associated with a more advanced tumor stage [54]. The detection rate of TC in children and adolescents before the Chernobyl disaster was lower in the former SU than in other industrialized parts of the world $[13,23,24]$. The screening in the contaminated territories was productive because many old neglected cases were found. This fact is often 
disregarded in the literature. For example, Fridman et al., wrote that the frequency of sporadic TC in the former SU in the period 1971-85 did not differ from global statistics [55] referring to the study of Williams [18], where no such statements were found. Balonov wrote about the background of TC incidence in children $\leq 10$ years old of $2-4$ cases/ million/year [56]. However, in Belorussia only 3 pediatric ( $\leq 15$ years old) with TC were diagnosed during 1981-85 (incidence rate $\sim 0.3$ cases/million/ year). For the whole of Ukraine, the statistics were correspondingly 25 and 0.5 and for its northern regions -1.0 and 0.1 [24]. The above-cited figures are low in comparison with other developed countries $[13,23]$, which means that there was a reservoir of neglected cancers. It is known that the screening can enhance a registered TC incidence 10 -fold or more $[5,57]$ due to a "reservoir of clinically silent cancers" [58]. Finally, with regard to the cleanup workers (liquidators), it should be considered that many of them underwent regular medical checkups $[59,60]$ i.e. the surveillance bias has taken place $[14,15]$.

\section{CONCLUSION}

There is evidence that RET rearrangements in PTC, especially RET/PTC3, tend to correlate with the tumor progression. In the future, relationships between different types of RET/PTC, tumor dimensions, stage, and grade should be tested quantitatively. Further data collection on the frequency of different RET/PTC fusion types in less developed countries may provide more evidence in support of the association between RET/PTC3 and the tumor progression i.e. averagely later tumor detection. If the hypothesis presented here is correct, a low prevalence of RET/ PTC3 among sporadic TC cases could be seen as a statistical indicator of efficient TC diagnosis and early detection in a given population.

\section{ACKNOWLEDGMENTS}

Not applicable.

\section{CONFLICT OF INTEREST}

The authors declared no conflict of interest.

\section{ETHICS APPROVAL}

Not applicable.

\section{REFERENCES}

1. Romei C, Elisei R. RET/PTC Translocations and Clinico-Pathological Features in Human Papillary Thyroid Carcinoma. Front Endocrinol (Lausanne). 2012;3(54). DOI: $10.3389 /$ fendo.2012.00054 PMID: 22654872.

2. DeLellis RA, Shin SJ, Treaba DO. Immunohistology of Endocrine Tumors. In: Dabbs DJ, editor. Diagnostic immunohistochemistry: Theranostic and genomic applications. 3rd ed. Philadelphia: W.B. Saunders; 2010. p. 291-339. DOI: 10.1016/B978-1-4160-5766-6.00014-5.

3. Trovisco V, Soares P, Preto A, Castro P, Máximo V, Sobrinho-Simões M. Molecular genetics of papillary thyroid carcinoma: great expectations. Arq Bras Endocrinol Metabol. 2007;51:643-53. DOI: 10.1590/S000427302007000500002 PMID: 17891228.

4. Cordioli MI, Moraes L, Bastos A, P B, Alves M, Delcelo R, et al. Fusion Oncogenes Are the Main Genetic Events Found in Sporadic Papillary Thyroid Carcinomas from Children. Thyroid. 2017;27(2):182-8. DOI: 10.1089/ thy.2016.0387 PMID: 27849443.

5. Jaworowski Z. Observations on the Chernobyl Disaster and LNT. Dose Response. 2010;8(2):dose-response.09-029.Jaworowski. DOI: 10.2203/dose-response.09-029.Jaworowski PMID: 20585443.

6. Shibamoto Y, Nakamura H. Overview of Biological, Epidemiological, and Clinical Evidence of Radiation Hormesis. Int J Mol Sci. 2018;19(8). DOI: 10.3390/ ijms19082387 PMID: 30104556.

7. Sacks B, Meyerson G, Siegel JA. Epidemiology Without Biology: False Paradigms, Unfounded Assumptions, and Specious Statistics in Radiation Science (with Commentaries by Inge Schmitz-Feuerhake and Christopher Busby and a Reply by the Authors). Biol Theory. 2016;11:69-101. DOI: 10.1007/s13752-016-0244-4 PMID: 27398078 .

8. Ivanov VK, Maksioutov MA, Chekin SY, Petrov AV, Biryukov AP, Kruglova $Z$ G, et al. The risk of radiation-induced cerebrovascular disease in Chernobyl emergency workers. Health Phys. 2006;90(3):199-207. DOI: 10.1097/01.HP.0000175835.31663.ea PMID: 16505616.

9. Kashcheev VV, Chekin SY, Maksioutov MA, Tumanov KA, Menyaylo AN, Kochergina EV, et al. Radiation-epidemiological Study of Cerebrovascular Diseases in the Cohort of Russian Recovery Operation Workers of the Chernobyl Accident. Health Phys. 2016;111(2):192-7. DOI: 10.1097/HP.0000000000000523 PMID: 27356064.

10. Azizova TV, Grigoryeva ES, Haylock RG, Pikulina MV, Moseeva MB. Ischaemic heart disease incidence and mortality in an extended cohort of Mayak workers first employed in 1948-1982. Br J Radiol. 2015;88(1054):20150169. DOI: 10.1259/bjr.20150169 PMID: 26224431.

11. Moseeva MB, Azizova TV, Grigoryeva ES, Haylock R. Risks of circulatory diseases among Mayak PA workers with radiation doses estimated using the improved 
Mayak Worker Dosimetry System 2008. Radiat Environ Biophys. 2014;53(2):469-77. DOI: 10.1007/s00411014-0517-x PMID: 24482017.

12. Little MP, Tawn EJ, Tzoulaki I, Wakeford R, Hildebrandt G, Paris F, et al. Review and meta-analysis of epidemiological associations between low/moderate doses of ionizing radiation and circulatory disease risks, and their possible mechanisms. Radiat Environ Biophys. 2010;49(2):139-53. DOI: 10.1007/s00411-009-0250-Z PMID: 19862545.

13. Jargin SV. Chernobyl-Related Cancer and Precancerous Lesions: Incidence Increase vs. Late Diagnostics. Dose Response. 2014;12(3):404-14. DOI: 10.2203/dose-response.13-039.Jargin PMID: 25249833.

14. Jargin SV. Hormesis and radiation safety norms: Comments for an update. Hum Exp Toxicol. 2018;37(11):123343. DOI: 10.1177/0960327118765332 PMID: 29607734.

15. Jargin S. The overestimation of medical consequences of low-dose exposure to ionizing radiation. Newcastle upon Tyne: Cambridge Scholars Publishing; 2019. 160 p.

16. Jargin SV. On the RET Rearrangements in Chernobyl-Related Thyroid Cancer. J Thyroid Res. 2012;2012:373879. DOI: 10.1155/2012/373879 PMID: 22175034.

17. Jargin SV. Thyroid cancer after Chernobyl: mechanisms of overestimation. Radiat Environ Biophys. 2011;50(4):603-4; author reply 5-6. DOI: 10.1007/ S00411-011-0379-4 PMID: 21858516.

18. Williams D. Radiation carcinogenesis: lessons from Chernobyl. Oncogene. 2008;27 Suppl 2:S9-18. DOI: 10.1038/onc.2009.349 PMID: 19956182.

19. Rabes HM, Demidchik EP, Sidorow JD, Lengfelder E, Beimfohr C, Hoelzel D, et al. Pattern of radiation-induced RET and NTRK1 rearrangements in 191 post-chernobyl papillary thyroid carcinomas: biological, phenotypic, and clinical implications. Clin Cancer Res. 2000;6(3):1093-103. PMID: 10741739.

20. Prescott JD, Zeiger MA. The RET oncogene in papillary thyroid carcinoma. Cancer. 2015;121(13):2137-46. DOI: $10.1002 /$ cncr.29044 PMID: 25731779.

21. Williams ED, Abrosimov A, Bogdanova T, Demidchik EP, Ito M, LiVolsi V, et al. Thyroid carcinoma after Chernobyl latent period, morphology and aggressiveness. Br J Cancer. 2004;90(11):2219-24. DOI: 10.1038/ sj.bjc.6601860 PMID: 15150580 .

22. Yablokov AV. Oncological diseases after the Chernobyl catastrophe. Ann N Y Acad Sci. 2009;1181:161-91. DOI: 10.1111/j.1749-6632.2009.04827.x PMID: 20002046.

23. Demidchik YE, Saenko VA, Yamashita S. Childhood thyroid cancer in Belarus, Russia, and Ukraine after Chernobyl and at present. Arq Bras Endocrinol Metabol. 2007;51(5):748-62. DOI: 10.1590/s000427302007000500012 PMID: 17891238.

24. Stsjazhko VA, Tsyb AF, Tronko ND, Souchkevitch G, Baverstock KF. Childhood thyroid cancer since accident at Chernobyl. BMJ. 1995;310(6982):801. DOI: 10.1136/ bmj.310.6982.801 PMID: 7711589

25. Yip L, Nikiforova MN, Yoo JY, McCoy KL, Stang MT, Armstrong MJ, et al. Tumor genotype determines phenotype and disease-related outcomes in thyroid cancer: a study of 1510 patients. Ann Surg. 2015;262(3):519-25; discussion 24-5. DOI: 10.1097/SLA.0000000000001420 PMID: 26258321.

26. Rhoden KJ, Johnson C, Brandao G, Howe JG, Smith BR, Tallini G. Real-time quantitative RT-PCR identifies distinct c-RET, RET/PTC1 and RET/PTC3 expression patterns in papillary thyroid carcinoma. Lab Invest. 2004;84(12):1557-70. DOI: 10.1038/labinvest.3700198 PMID: 15502856.

27. Nikiforov YE. Molecular diagnostics of thyroid tumors. Arch Pathol Lab Med. 2011;135(5):569-77. DOI: 10.1043/2010-0664-RAIR.1 PMID: 21526955.

28. Rao PJ, Vardhini NV, Parvathi MV, Murthy PB, Sudhakar G. Prevalence of RET/PTC1 and RET/PTC3 gene rearrangements in Chennai population and its correlation with clinical parameters. Tumour Biol. 2014;35(10):9539-48. DOI: 10.1007/s13277-0141909-x PMID: 24957039.

29. Khan MS, Qadri Q, Makhdoomi MJ, Wani MA, Malik AA, Niyaz M, et al. RET/PTC Gene Rearrangements in Thyroid Carcinogenesis: Assessment and Clinico-Pathological Correlations. Pathol Oncol Res. 2020;26(1):50713. DOI: $10.1007 / \mathrm{s} 12253-018-0540-3$ PMID: 30467698.

30. Bounacer A, Wicker R, Caillou B, Cailleux AF, Sara$\sin \mathrm{A}$, Schlumberger M, et al. High prevalence of activating ret proto-oncogene rearrangements, in thyroid tumors from patients who had received external radiation. Oncogene. 1997;15(11):1263-73. DOI: $10.1038 /$ sj.onc.1200206 PMID: 9315093.

31. Williams ED, Abrosimov A, Bogdanova T, Demidchik EP, Ito M, LiVolsi V, et al. Morphologic characteristics of Chernobyl-related childhood papillary thyroid carcinomas are independent of radiation exposure but vary with iodine intake. Thyroid. 2008;18(8):847-52. DOI: 10.1089/thy.2008.0039 PMID: 18651805 .

32. Vuong HG, Altibi AM, Abdelhamid AH, Ngoc PU, Quan VD, Tantawi MY, et al. The changing characteristics and molecular profiles of papillary thyroid carcinoma over time: a systematic review. Oncotarget. 2017;8(6):1063749. DOI: 10.18632/oncotarget.12885 PMID: 27793009.

33. Mitsutake N, Fukushima T, Matsuse M, Rogounovitch T, Saenko V, Uchino S, et al. BRAF(V600E) mutation is highly prevalent in thyroid carcinomas in the young population in Fukushima: a different oncogenic profile from Chernobyl. Sci Rep. 2015;5:16976. DOI: 10.1038/ srep16976 PMID: 26584635.

34. Caudill CM, Zhu Z, Ciampi R, Stringer JR, Nikiforov YE. Dose-dependent generation of RET/PTC in human thyroid cells after in vitro exposure to gamma-radiation: a model of carcinogenic chromosomal rearrangement induced by ionizing radiation. J Clin Endocrinol Metab. 2005;90(4):2364-9. DOI: 10.1210/jc.2004-1811 PMID: 


\section{5.}

35. Nikiforov YE. Is ionizing radiation responsible for the increasing incidence of thyroid cancer? Cancer. 2010;116(7):1626-8. DOI: 10.1002/cncr.24889 PMID: 20151420.

36. Unger K, Zitzelsberger H, Salvatore G, Santoro M, Bogdanova T, Braselmann H, et al. Heterogeneity in the distribution of RET/PTC rearrangements within individual post-Chernobyl papillary thyroid carcinomas. J Clin Endocrinol Metab. 2004;89(9):4272-9. DOI: 10.1210/ jc. 2003-031870 PMID: 15356021.

37. Di Cristofaro J, Vasko V, Savchenko V, Cherenko S, Larin A, Ringel MD, et al. ret/PTC1 and ret/PTC3 in thyroid tumors from Chernobyl liquidators: comparison with sporadic tumors from Ukrainian and French patients. Endocr Relat Cancer. 2005;12(1):173-83. DOI: 10.1677/ erc.1.00884 PMID: 15788648.

38. Romei C, Fugazzola L, Puxeddu E, Frasca F, Viola D, Muzza M, et al. Modifications in the papillary thyroid cancer gene profile over the last 15 years. J Clin Endocrinol Metab. 2012;97(9):E1758-65. DOI: 10.1210/ jc.2012-1269 PMID: 22745248.

39. Jung CK, Little MP, Lubin JH, Brenner AV, Wells SA, Jr., Sigurdson AJ, et al. The increase in thyroid cancer incidence during the last four decades is accompanied by a high frequency of BRAF mutations and a sharp increase in RAS mutations. J Clin Endocrinol Metab. 2014;99(2):E276-85. DOI: 10.1210/jc.2013-2503 PMID: 24248188 .

40. Leeman-Neill RJ, Brenner AV, Little MP, Bogdanova TI, Hatch M, Zurnadzy LY, et al. RET/PTC and PAX8/PPARgamma chromosomal rearrangements in post-Chernobyl thyroid cancer and their association with iodine-131 radiation dose and other characteristics. Cancer. 2013;119(10):1792-9. DOI: 10.1002/cncr.27893 PMID: 23436219.

41. Tuttle RM, Lukes Y, Onstad L, Lushnikov E, Abrosimov A, Troshin V, et al. ret/PTC activation is not associated with individual radiation dose estimates in a pilot study of neoplastic thyroid nodules arising in Russian children and adults exposed to Chernobyl fallout. Thyroid. 2008;18(8):839-46. DOI: 10.1089/thy.2008.0072 PMID: 18690796.

42. Jargin S. Dose and dose-rate effectiveness of radiation: First objectivity then conclusions. J Environ Occup Sci. 2016;5(1):25-9. DOI: 10.5455/jeos.20160412075846.

43. Suzuki K, Saenko V, Yamashita S, Mitsutake N. Radiation-Induced Thyroid Cancers: Overview of Molecular Signatures. Cancers (Basel). 2019;11(9). DOI: 10.3390/ cancers11091290 PMID: 31480712.

44. Koterov AN, Ushenkova LN, Biryukov AP, Samoilov AS. RET/PTC gene rearrangements frequency in papillary thyroid carcinoma worldwide depending on time after Chernobyl nuclear power plant accident (pooled analysis). Possible contribution of factors of diagnosis, 'aggressive surgery', radiation, and age. . Med Radiol
Radiat Saf. 2016;61(5):27-41.

45. Viglietto G, Chiappetta G, Martinez-Tello FJ, Fukunaga FH, Tallini G, Rigopoulou D, et al. RET/PTC oncogene activation is an early event in thyroid carcinogenesis. Oncogene. 1995;11(6):1207-10. PMID: 7566982.

46. Corvi R, Martinez-Alfaro M, Harach HR, Zini M, Papotti M, Romeo G. Frequent RET rearrangements in thyroid papillary microcarcinoma detected by interphase fluorescence in situ hybridization. Lab Invest. 2001;81(12):1639-45. DOI: 10.1038/labinvest.3780377 PMID: 11742034.

47. Sugg SL, Ezzat S, Rosen IB, Freeman JL, Asa SL. Distinct multiple RET/PTC gene rearrangements in multifocal papillary thyroid neoplasia. J Clin Endocrinol Metab. 1998;83(11):4116-22. DOI: 10.1210/jcem.83.11.5271 PMID: 9814501.

48. Tallini G, Santoro M, Helie M, Carlomagno F, Salvatore G, Chiappetta G, et al. RET/PTC oncogene activation defines a subset of papillary thyroid carcinomas lacking evidence of progression to poorly differentiated or undifferentiated tumor phenotypes. Clin Cancer Res. 1998;4(2):287-94. PMID: 9516913.

49. Jargin SV. RET/PTC3 Rearrangement in Papillary Thyroid Carcinoma: Possible Marker of Tumor Progression. Ann Surg. 2017;266(6):e120-e1. DOI: 10.1097/ SLA.0000000000002031 PMID: 27849670.

50. Nikita ME, Jiang W, Cheng SM, Hantash FM, McPhaul MJ, Newbury RO, et al. Mutational Analysis in Pediatric Thyroid Cancer and Correlations with Age, Ethnicity, and Clinical Presentation. Thyroid. 2016;26(2):227-34. DOI: 10.1089/thy.2015.0401 PMID: 26649796.

51. Su X, Li Z, He C, Chen W, Fu X, Yang A. Radiation exposure, young age, and female gender are associated with high prevalence of RET/PTC1 and RET/PTC3 in papillary thyroid cancer: a meta-analysis. Oncotarget. 2016;7(13). DOI: 10.18632/oncotarget.7574.

52. Smida J, Salassidis K, Hieber L, Zitzelsberger H, Kellerer AM, Demidchik EP, et al. Distinct frequency of ret rearrangements in papillary thyroid carcinomas of children and adults from Belarus. Int J Cancer. 1999;80(1):32-8. DOI: $10.1002 /($ sici) 1097-0215(19990105)80:1<32::Aidijc7>3.0.Co;2-1.

53. Akulevich NM, Saenko VA, Rogounovitch TI, Drozd VM, Lushnikov EF, Ivanov VK, et al. Polymorphisms of DNA damage response genes in radiation-related and sporadic papillary thyroid carcinoma. Endocr Relat Cancer. 2009;16(2):491-503. DOI: $10.1677 /$ ERC-08-0336 PMID: 19286843 .

54. Bogdanova TI, Zurnadzhy LY, Greenebaum E, McConnell RJ, Robbins J, Epstein OV, et al. A cohort study of thyroid cancer and other thyroid diseases after the Chornobyl accident: pathology analysis of thyroid cancer cases in Ukraine detected during the first screening (19982000). Cancer. 2006;107(11):2559-66. DOI: 10.1002/ cncr.22321 PMID: 17083123.

55. Fridman MV, Man'kovskaia SV, Kras'ko OV, Demidchik 
Iu E. [Clinical and morphological features of papillary thyroid cancer in children and adolescents in the Republic of Belarus: analysis of 936 post-Chernobyl carcinomas]. Vopr Onkol. 2014;60(2):43-6. PMID: 24919260.

56. Balonov MI. Health and Environmental Effects of the Chernobyl Accident Presented in the UNSCEAR Report 2008: Lessons for Nuclear Emergency Response. Med Radiol Radiat Saf. 2011;56(6):15-23.

57. UNSCEAR 1994 Report. Sources and Effects of Ionizing Radiation. Annex A. Epidemiological studies of radiation carcinogenesis. New York: United Nations; 1994.
58. Paulson VA, Rudzinski ER, Hawkins DS. Thyroid Cancer in the Pediatric Population. Genes (Basel). 2019;10(9). DOI: 10.3390/genes10090723 PMID: 31540418.

59. UNSCEAR 2008 Report. Sources and effects of ionizing radiation. Annex D. Health effects due to radiation from the Chernobyl accident. New York: United Nation; 2008.

60. Rahu K, Hakulinen T, Smailyte G, Stengrevics A, Auvinen A, Inskip PD, et al. Site-specific cancer risk in the Baltic cohort of Chernobyl cleanup workers, 1986-2007. Eur J Cancer. 2013;49(13):2926-33. DOI: 10.1016/j. ejca.2013.04.014 PMID: 23683549. 